\title{
Cell Cycle Phase-Specific Surface Expression of Nerve Growth Factor Receptors TrkA and p75
}

\author{
José Luis Urdiales, ${ }^{1}$ Elena Becker, ${ }^{2}$ Muriel Andrieu, ${ }^{1}$ Annie Thomas, ${ }^{1}$ Jérôme Jullien, ${ }^{1}$ Leo A. van Grunsven, ${ }^{1}$ \\ Sophie Menut, ${ }^{1}$ Gerard I. Evan, ${ }^{3}$ Dionisio Martín-Zanca, ${ }^{2}$ and Brian B. Rudkin ${ }^{1}$ \\ ${ }^{1}$ Laboratoire de Biologie Moléculaire et Cellulaire, Unité Mixte de Recherche 49, Centre National de la Recherche \\ Scientifique, Ecole Normale Supérieure de Lyon, 69364 Lyon Cedex 07, France, 2Instituto de Microbiología Bioquímica, \\ Consejo Superior de Investigaciones Científicas, Universidad de Salamanca, 37007 Salamanca, Spain, and $3 /$ mperial \\ Cancer Research Fund, London WC2A 3PX, United Kingdom
}

Expression of the nerve growth factor (NGF) receptors TrkA and $\mathrm{p} 75^{\text {NTR }}$ was found to vary at the surface of PC12 cells in a cell cycle phase-specific manner. This was evidenced by using flow cytometric and microscopic analysis of cell populations labeled with antibodies to the extracellular domains of both receptors. Differential expression of these receptors also was evidenced by biotinylation of surface proteins and Western analysis, using antibodies specific for the extracellular domains of TrkA and $\mathrm{p} 75^{\mathrm{NTR}}$. TrkA is expressed most strongly at the cell surface in M and early G1 phases, whereas $p 75^{\text {NTR }}$ is expressed mainly in late $\mathrm{G} 1, \mathrm{~S}$, and $\mathrm{G} 2$ phases. This expression reflects the molec- ular and cellular responses to NGF in specific phases of the cell cycle; in the G1 phase NGF elicits both the anti-mitogenic effect, i.e., inhibition of the $\mathrm{G} 1$ to $\mathrm{S}$ transition, and the differentiation response whereas a survival effect is provoked elsewhere in the cell cycle. A model is proposed relating these responses to the surface expression of the two receptors. These observations open the way for novel approaches to the investigation of the mechanism of NGF signal transduction.

Key words: signaling; PC12 cells; TrkA antibodies; p75 NTR antibodies; flow cytometry; cell cycle; neurotrophin; receptor
Nerve growth factor (NGF) is the prototypic member of the neurotrophin family of growth factors. Several cell types of neural crest origin require NGF for survival both in vivo and in vitro (Yankner and Shooter, 1982). Study of the mechanism by which NGF exerts its action is complicated by the presence of two

Received Feb. 17, 1998; revised May 29, 1998; accepted June 8, 1998.

This work was supported by grants from the Association pour la Recherche contre le Cancer (ARC; 1394), the Ligue National Contre le Cancer (LNCC; Axe Oncogénèse et Signalization), the Rhône-Alpes Region, the Centre National de la Recherche Scientifique (Concerted French/Spanish Exchange program PICASSO), and the Spanish Ministry for Science and Education. J.L.U. is a recipient of a Marie Curie Postdoctoral Fellowship from the European Union and fellowships from the LNCC, Comités départementales de la Saône et Loire et de l'Ain. E.B. is a recipient of a fellowship from the Spanish Ministry for Science and Education through the Consejo Superior de Investigaciones Científicas. L.A.v.G. was supported by grants from the AUTODESK DEVELOPMENT, BV, the French Ministry of Foreign Affairs, the LNCC, and the ARC. B.B.R., D.M.Z., and G.I.E. acknowledge funding for a concerted action network within the European Union Biomed 1 Cancer Research program (BMH1-CT94-1471) and a shared-cost network under the Biomed 2 Brain Research program (BMH4-CT96-0010). We thank Dr. M. Chao for generously supplying antibodies against $\mathrm{p} 75^{\mathrm{NTR}}$, Dr. L. F. Reichardt for generously providing polyclonal antibodies against TrkA and $\mathrm{p} 75^{\mathrm{NTR}}$, Dr. S. Menard for the MGR-12 monoclonal antibodies against TrkA, Dr. T. Mitsiadis for 192-IgG antibodies against $\mathrm{p} 75^{\mathrm{NTR}}$ and for stimulating discussions, and Dr. G. Guroff for his generous gifts of NGF and PC12 cells. We also thank A. Defours for assistance in the preparation of this manuscript.

Correspondence should be addressed to Dr. Brian Rudkin at the above address. Dr. Urdiales's present address: Laboratorio de Bioquímica y Biología Molecular, Facultad de Ciencias, Universidad de Málaga, Campus de Teatinos s/n, 29071 Málaga, Spain.

Dr. Becker's present address: Skirball Institute for Biomolecular Medicine, New York University Medical Center, 550 First Avenue, New York, NY 10016.

Dr. Andrieu's present address: CHU Cochin Port-Royal, Institut National de la Santé et de la Recherche Médicale, 27 Rue du Faubourg, 75674 Paris, France.

Dr. van Grunsven's present address: National Institutes of Health, National Institute of Neurological Diseases, LMB Building 36, Room 5A29, 36 Convent Drive, Bethesda, MD 20892-4152.

Dr. Menut's present address: Institut Jacques Monod, Unité Mixte de Recherche 9922, Centre National de la Recherche Scientifique, 2 Place Jussieu, 75251 Paris Cedex 05, France.

Copyright (C) 1998 Society for Neuroscience $\quad 0270-6474 / 98 / 186767-09 \$ 05.00 / 0$ receptors, the neurotrophin receptor $\mathrm{p} 75^{\mathrm{NTR}}$ (Chao, 1994) and the receptor TrkA (Kaplan et al., 1991; Barbacid, 1994). Whereas some reports indicate that both receptors are required to transmit the NGF signal for differentiation (Lee et al., 1992; Battleman et al., 1993), others suggest that TrkA alone may be sufficient for certain actions (Jing et al., 1992) and p $75^{\text {NTR }}$ for others, such as the regulation of apoptosis (Rabizadeh et al., 1993; CasacciaBonnefil et al., 1996; Frade et al., 1996). PC12 cells, derived from a pheochromocytoma tumor of the rat adrenal medulla (Greene and Tischler, 1976), have become a principal model for the study of the NGF action. In the absence of NGF these cells proliferate and resemble chromaffin cells in their capacity to synthesize, store, and release catecholamines. In response to NGF, these cells stop dividing and extend neurites, differentiating into acetylcholinergic cells similar to those of the sympathetic nervous system.

Rudkin and colleagues (1989) have presented evidence for the cell cycle phase-specifc action of NGF. This neurotrophic factor can have a dual action on PC12 cells. During the G1 phase they respond to NGF by differentiating, whereas in the other phases NGF permits progression through the cell cycle. The antiproliferative effect of NGF corresponds to an accumulation of cells in the G1 phase of the cell cycle resulting from a block of the G1-to-S transition (van Grunsven et al., 1996a,b). NGF signal transduction is cell cycle phase-specific, as exemplified by a strong induction of the proto-oncogene c-fos in G1 phase but by little or no induction in the S or G2 phase (Rudkin et al., 1989). Because signal transduction starts at the receptors, the expression of those for NGF were investigated on PC12 cells in relation to the cell cycle.

Differential expression of the NGF receptor TrkA and the neurotrophin receptor $\mathrm{p} 75^{\mathrm{NTR}}$ has been observed at the extracellular surface of exponentially growing PC12 cells. TrkA is 
expressed preferentially at the surface in early G1 and M phases of cell cycle and is not detectable in late G1, S, and G2 phases. Biotinylation of cell surface proteins in synchronized cultures has confirmed the differential surface expression of NGF receptors. These observations offer new insight into the mechanism of NGF signal transduction.

\section{MATERIALS AND METHODS}

Antibodies. Three antibodies specific for rat $\mathrm{p} 75^{\mathrm{NTR}}$ were used: two different antibodies directed against the extracellular domain, the monoclonal antibody 192-IgG (1:1000 to 1:2000) (Boehringer Mannheim, France) or the rabbit serum REX (1:2000 to 1:4000) (from Dr. L. Reichardt, University of California, San Francisco, CA), and one rabbit serum containing antibodies directed against the intracellular portion of p75 NTR "9993" (from Dr. M. Chao, Skirball Institute, New York, NY). Two different antibodies against the extracellular domain of rat TrkA were used: the RTA antibody (from Dr. L. Reichardt) and the antibody 267 (Ab267), which was produced in rabbits against a synthetic peptide within the extracellular domain of rat TrkA, amino acids 267-285. For affinity purification, either the sera or the $\mathrm{IgG}$ preparation was applied to a column prepared by coupling the antigenic peptide to $\mathrm{CNBr}$-activated Sepharose CL-6B. Fractions containing antibody were pooled and concentrated to $\sim 0.5 \mathrm{mg}-1 \mathrm{mg} / \mathrm{ml}$. This antibody was used at concentrations of 1:50 to 1:100. The antibody Sc414 was directed against amino acids 777-790 at the C terminus of rat TrkA (Santa Cruz Biotechnology, Tebu, France) $(1: 40)$. Secondary antibodies for immunolabeling were affinitypurified sheep IgG (Boehringer Mannheim Biochemica, Bagnolet, France) or donkey $\mathrm{F}\left(\mathrm{Ab}^{\prime}\right)_{2}$ anti-mouse (Jackson ImmunoResearch, West Grove, PA) and goat IgG (Sigma, St. Louis, MO) or donkey F(Ab') (Jackson ImmunoResearch) anti-rabbit labeled with FITC or R-Phycoerythrin. These were used at dilutions of 1:100 to 1:200.

Cell culture. PC12 cells were cultured routinely, as previously described (Rudkin et al., 1989). Under these growth conditions the population doubling time was $48-52 \mathrm{hr}$. The protocol for synchronization of the cultures by serum starvation also was followed as described in Rudkin et al. (1989).

Immunolabeling. Cells were harvested by mechanical agitation in PBS and then used either as live intact cells (no fixation or permeabilization) or fixed for $15 \mathrm{~min}$ at room temperature with $1 \%$ paraformaldehyde. The cells were treated with blocking buffer [ $2 \%$ bovine serum albumin (BSA; Sigma), $10 \%$ fetal calf serum (Life Technologies, Gaithersburg, MD), PBS $\mathrm{Ca}^{2+}$ - and $\mathrm{Mg}^{2+}$-free (TechGen International, Paris, France) or DMEM (Life Technologies), and $0.02 \%$ sodium azide as preservative] and then exposed to appropriate dilutions of antibody in blocking buffer for $20 \mathrm{~min}$ on ice. After three washes in PBS, the cells were exposed to FITC- or Phycoerythrin-labeled second antibody used at dilutions of 1:200 in blocking buffer for $20 \mathrm{~min}$ on ice. For intracellular labeling the cells were grown on collagen poly-L-lysine-coated coverslips and fixed for 3 min with methanol $\left(-20^{\circ} \mathrm{C}\right)$. Microscopic observation was with an Olympus Vanox AH2 fluorescence microscope (Tokyo, Japan).

Analysis of cell cycle distribution, subsequent to surface labeling with antibodies, was performed by fixing the cells in cold $\left(-20^{\circ} \mathrm{C}\right) 70 \%$ ethanol for $30 \mathrm{~min}$ on ice, followed by one wash in PBS and treatment with RNase [Type 1 bovine pancreas (Sigma), $1 \mathrm{mg} / \mathrm{ml}$ PBS, and $0.13 \mathrm{~mm}$ EGTA] for $10 \mathrm{~min}$ at room temperature. Before analysis, propidium iodide (PI) was added to a final concentration of $5 \mu \mathrm{g} / \mathrm{ml}$. Alternatively, Hoechst 33342 (HO42) was added to cell suspensions at a final concentration of $0.12 \mu \mathrm{g} / \mathrm{ml}$. Cells were analyzed by flow cytometry as described below.

Flow cytometric analysis. Cells were immunolabeled as described above. Analysis was performed on a FACStar Plus flow cytometer (Becton Dickinson, Paris, France) equipped with a $100 \mathrm{~mW}$ argon laser tuned to $488 \mathrm{~nm}$ (Ion Laser Technology, Salt Lake City, UT). Emission fluorescence was measured with a DF 530/30 filter for FITC and a DF $575 / 26$ filter for Phycoerythrin. When the fluorochrome Hoechst (HO42) was used, excitation was made with an INNOVA 300 ion laser tuned to multiline UV with $\mathrm{HO} 42$ emission fluorescence measured via a DF 424/44 filter. Data acquisition and analysis were performed with Lysis II software on a consort 340 computer (Hewlett Packard, Palo Alto, CA) or with CellQuest software on an Apple Macintosh 650 Quadra computer. In some experiments the cells were analyzed on a FACScan flow cytometer (Becton Dickinson) equipped with an argon ion laser tuned to 488 $\mathrm{nm}$. Emission fluorescence was measured with a DF 530 filter for FITC and a DF 585 filter for PI.
Biotinylation of surface proteins. PC12 cells were synchronized by serum starvation and restimulated by serum addition, as previously described (Rudkin et al., 1989). At selected times the cells were harvested and biotinylated with the ECL protein biotinylation kit (Amersham, Les Ulis, France) according to the manufacturer's instructions. Cells were treated with lysis buffer [containing (in mM) 20 Tris-HCl, $\mathrm{pH} 8,137 \mathrm{NaCl}, 2$ EDTA, 1.1 phenylmethylsulfonyl fluoride (PMSF), and 1 sodium vanadate plus $10 \%$ glycerol, $1 \%$ Nonidet P-40, $0.15 \mathrm{U} / \mathrm{ml}$ aprotinin, and $20 \mu \mathrm{M}$ leupeptin], and equivalent amounts of cells were precipitated with streptavidin-Sepharose (Pierce, Rockford, IL). Affinity precipitation and Western blotting were performed as previously described (van Grunsven et al., 1996a). Filters were analyzed by means of enhanced chemofluorescence (ECF; Amersham) according to the manufacturer's instructions, using a Storm PhosphorImager (Molecular Dynamics, Sunnyvale, CA). The values obtained for TrkA or $\mathrm{p} 75^{\mathrm{NTR}}$ were normalized to the signal obtained in serum-starved cells (considered as one).

\section{RESULTS}

\section{Expression of NGF receptors}

Exponentially growing PC12 cells were exposed to antibodies against the NGF receptors TrkA or p $75^{\mathrm{NTR}}$ and observed by immunofluorescence under various experimental conditions. When paraformaldehyde-fixed, but nonpermeabilized, cells were exposed to antibodies against the extracellular domain of TrkA (e.g., RTA or Ab267), only a relatively small number of the cells in an exponentially growing population was labeled (routinely 10-30\%) (Fig. 1A,B). Similar quantitative results were obtained when nonfixed cells were used, i.e., between 5 and $30 \%$ of the cell population was labeled. When several antibodies against specific sequences within the extracellular domain of TrkA were used simultaneously, the fluorescence intensity of the signal increased with no change in the percentage of cells labeled. Microscopic observation, after fixation and permeabilization, indicated that all of the cells expressed TrkA intracellularly in a perinuclear location (Fig. $1 E, F$ ). This distribution resembles that of membrane proteins, which are stored intracellularly (e.g., the glucose transporter Glut4) (Rea and James, 1997). When an antibody against the extracellular domain of p75 ${ }^{\text {NTR }}(192-\mathrm{IgG})$ was used on nonpermeabilized cells, between 70 and $95 \%$ of the population was labeled at the cell surface (Fig. $1 C, D$ ). Similar results were obtained with REX antibody. In permeabilized cells the labeling was also present at the cell membrane (Fig. $1 G, H$ ). This labeling pattern is characteristic of membrane proteins that are addressed constitutively to the plasma membrane (e.g., EGF receptor) (Ekstrand et al., 1995).

\section{Differential surface expression of TrkA and p75 ${ }^{\text {NTR }}$}

Figure 2 illustrates the results of a typical double-labeling experiment of nonfixed cells, using an affinity-purified polyclonal antibody (Ab267) against the extracellular portion of TrkA and a monoclonal antibody against the extracellular domain of $\mathrm{p} 75^{\mathrm{NTR}}$ (192-IgG). Approximately $90 \%$ of the cells were p75 ${ }^{\text {NTR }}$-positive (Fig. 2b), and only $10 \%$ were positive for TrkA (Fig. 2c). When both antibodies were used, a population having both TrkA and p $75^{\text {NTR }}$ was observed (Fig. $2 d$ ). Similar observations were made by using RTA and other antibodies directed against the extracellular domain of TrkA (data not shown). These results suggest that the cell population is heterogeneous with regard to surface expression of NGF receptors. This heterogeneity would appear to be a reflection of the normal physiological state of the cell population. Sorting experiments wherein enrichment in a specific cell population was performed, followed by reculture, indicated that the original receptor distribution can be obtained within three to five population doublings (data not shown). 


\section{Surface labelling}

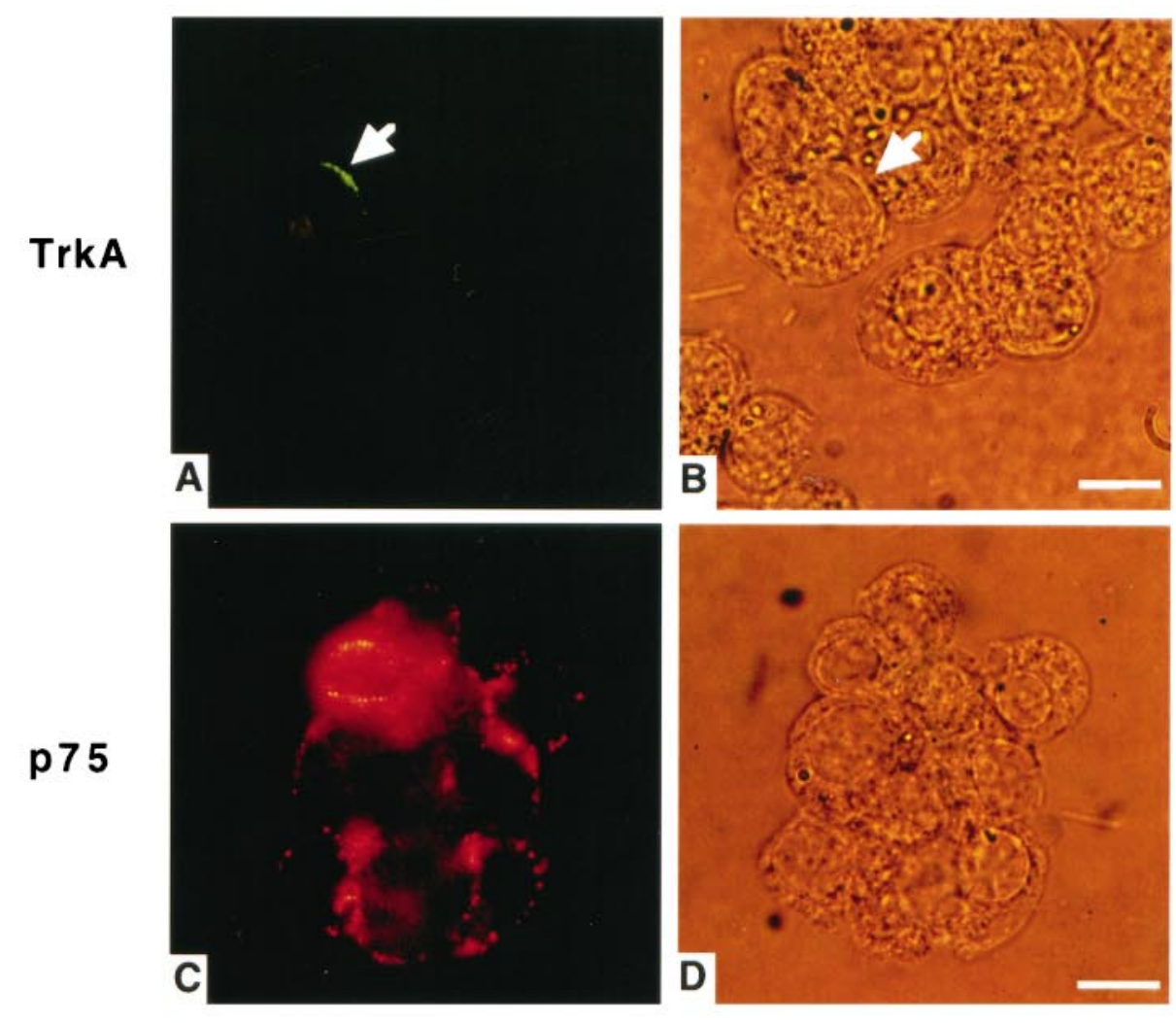

TrkA

\section{Intracellular labelling}

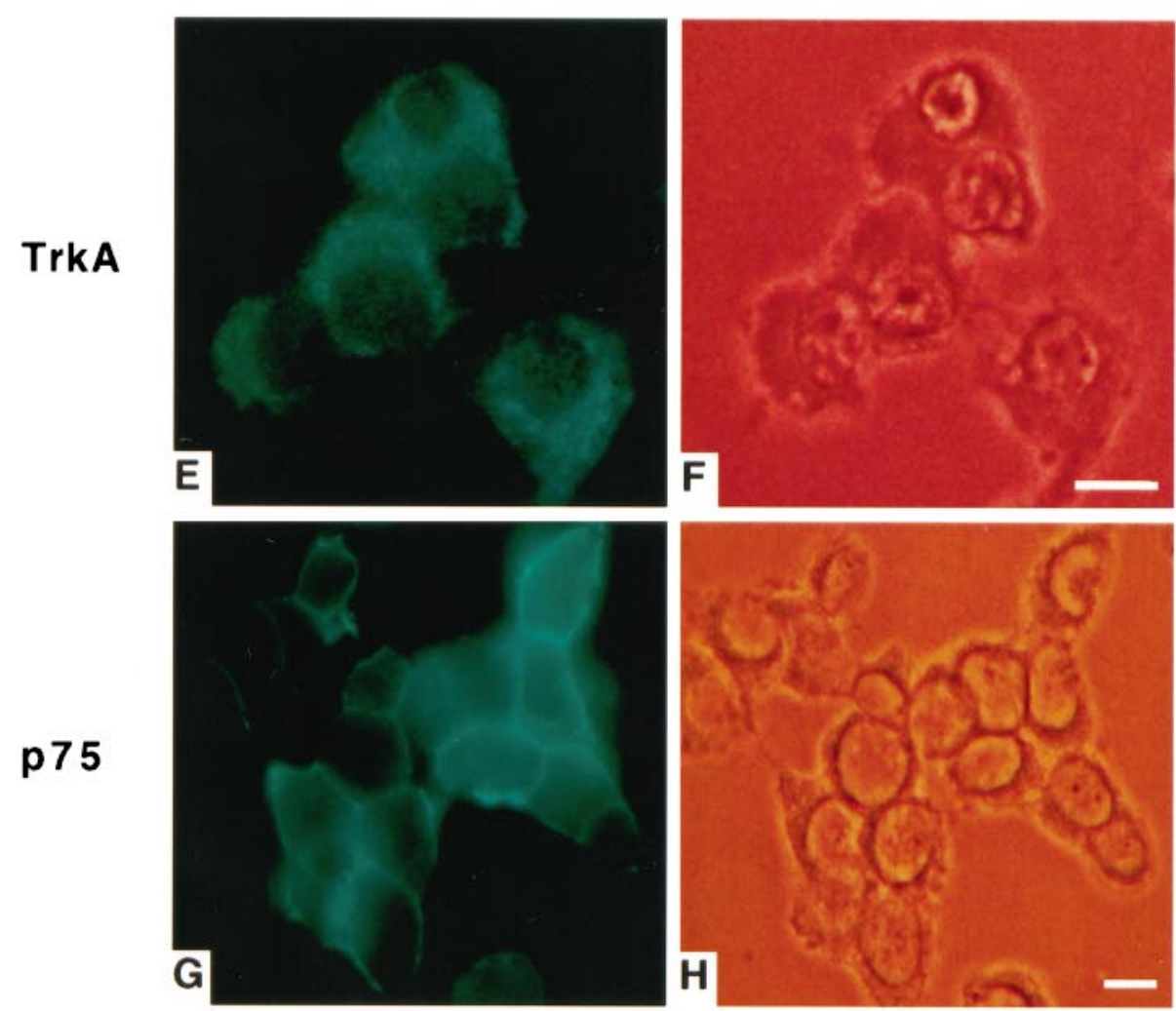

Figure 1. Expression of NGF receptors TrkA and $7^{2} 5^{\mathrm{NTR}}$. Cell surface localization is shown in $A$, TrkA (Ab267), and in $C$, p75 ${ }^{\mathrm{NTR}}(192-\mathrm{IgG}) . B, D$, Light microscopic views of the fields in $A$ and $B$, respectively. Intracellular localization is shown in $E$, TrkA (sc414), and in $G, \mathrm{p} 75^{\mathrm{NTR}}$ (REX). $F, H$, Light microscopic views of the fields in $E$ and $G$, respectively. Immunolabeling was performed as described in Materials and Methods. Scale bars, $10 \mu$ m. 



Figure 2. Flow cytometric analysis of $\mathrm{p}^{\mathrm{NTR}}$ and TrkA expression. Asynchronous cultures were exposed to 192-IgG (mouse monoclonal, $b$ ), affinity-purified Ab267 (rabbit polyclonal, $c$ ), or both together $(d)$, as described in Figure 1, without fixation. The second antibodies were Phycoerythrinlabeled anti-mouse and FITC-labeled anti-rabbit. The control $(a)$ is an incubation of both secondary antibodies together.

\section{A function of cell cycle phase?}

Our previous studies have indicated that the signal transmitted by NGF in PC12 cells is cell cycle phase-specific, e.g., the expression of the proto-oncogene c-fos was induced strongly in the G1 phase of the cell cycle but very weakly or not at all in S or G2 phase (Rudkin et al., 1989). The surface expression of NGF receptors was investigated throughout the cell cycle to evaluate if there is a correlation with the cell cycle phase-specific action of NGF. Figure 3 shows the expression of TrkA and $\mathrm{p} 75^{\mathrm{NTR}}$ during the cell cycle of exponentially growing PC12 cells as evidenced with flow cytometric analysis of asynchronous cultures. Although p $75^{\text {NTR }}$ is expressed in essentially all phases of the cell cycle (Fig. $3 b)$, TrkA is expressed mainly at the surface of cells with a $2 \mathrm{c}$ DNA content (i.e., G1) (Fig. 3c).

With the use of flow cytometry, the quantitation of relative cellular DNA content in combination with measurements of light scattering allows for identification of cells in the G2 phase separately from those in the $\mathrm{M}$ phase. In addition, this technique allows for the characterization of cells in early G1 and late G1 phases (Geido et al., 1990). Application of this approach offers a more detailed analysis of the NGF receptor expression throughout the cell cycle. Results obtained from PC12 cultures are shown to illustrate the clarity and precision of this type of analysis. Figure $4 A$ shows the expression of $\mathrm{p} 75^{\mathrm{NTR}}$ and TrkA in early $\mathrm{G} 1$, late G1, G2, and M phases of exponentially growing (i.e., asynchronous) PC12 cell cultures. TrkA is expressed most highly in the early G1 phase and at a lower level in the M phase of the cell cycle (Fig. 4Ai-l). Identical results were obtained with rat-1 fibroblasts expressing rat TrkA (data not shown).

In contrast, $\mathrm{p} 75^{\mathrm{NTR}}$ is present to varying extents in all phases (Fig. 4Ae-h), but its expression is higher in late G1 (Fig. 4Af) and in G2 phases (Fig. 4Ag) and lower in early G1 (Fig. 4Ae) and in $M$ phases (Fig. $4 A h$ ). Figure $4 B$ summarizes these results in the form of a model for $\mathrm{p} 75^{\mathrm{NTR}}$ and TrkA surface expression during the PC12 cell cycle. At the beginning of G1 the surface expression of p $75^{\mathrm{NTR}}$ is very low, increasing to a maximum level in late G1 phase. This high expression is maintained until the beginning of the $\mathrm{M}$ phase, when it drops again to a minimum level. TrkA surface expression appears in $\mathrm{M}$ phase, reaching a maximum in early G1, and then decreasing to a minimum level by late G1, remaining so until the next $\mathrm{M}$ phase. 

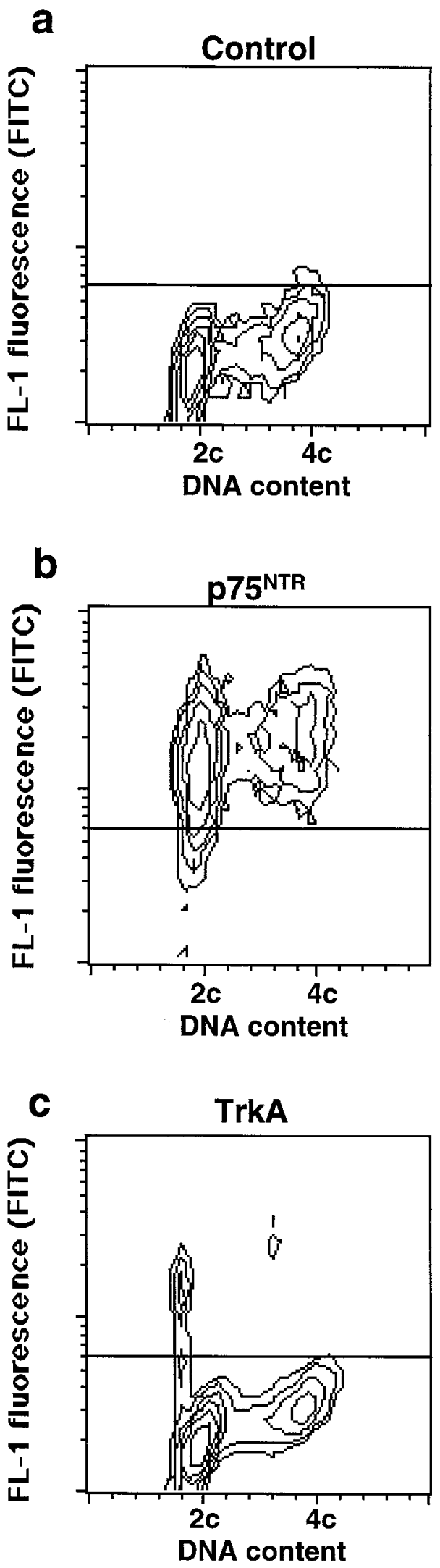

Figure 3. Cell cycle expression of NGF receptors. Shown are the simultaneous determination of cell cycle phase and the expression of $\mathrm{p} 75^{\mathrm{NTR}}$ (192-IgG, $b$ ) and TrkA (Ab267, rabbit polyclonal, $c$ ) of exponentially growing PC12 cells. The control $(a)$ is an incubation with a secondary antibody (FITC-labeled anti-rabbit) alone. Similar results were obtained

\section{Ratio of TrkA to $\mathrm{p} 75^{\mathrm{NTR}}$ during cell cycle}

Biotinylation of surface proteins was undertaken to study the expression of NGF receptors during the PC12 cell cycle. Cells were synchronized by serum starvation, as previously described (Rudkin et al., 1989). At the indicated times after restimulation with serum the cells were collected and biotinylated. Biotinylated proteins were precipitated with streptavidin-Sepharose and analyzed by Western blot. Figure $5 A$ shows a Western blot of biotinylated proteins, using the RTA antibody. A marked increase in the amount of TrkA can be observed at the cell surface between 37 and $52 \mathrm{hr}$ after serum restimulation, when cells are in M/early $\mathrm{G} 1$ phase. Figure $5 B$ illustrates that the amount of $\mathrm{p} 75^{\mathrm{NTR}}$ at the surface of PC12 cells changes only slightly throughout the cell cycle. No signal was detected when the blots were exposed with an antibody against the cytoskeletal protein tubulin (data not shown).

To quantitate the changes in the relative surface expression of NGF receptors during the cell cycle, we normalized the signals obtained for each receptor to the signal obtained in serumstarved cultures. Figure $5 C$ shows the variation in the relative amount of TrkA to p75 ${ }^{\mathrm{NTR}}$ after serum stimulation. A threefold increase in the ratio of TrkA to p $75^{\mathrm{NTR}}$ was observed between 37 and $52 \mathrm{hr}$, i.e., when cells were in $\mathrm{M}$ phase or early G1. In contrast, the ratio of TrkA to $\mathrm{p} 75^{\mathrm{NTR}}$ was lower in late G1, S, and G2 phases. These results confirm those obtained by using flow cytometric analysis of exponentially growing populations of cells labeled with antibodies toward the extracellular domain of each receptor, thereby validating this approach.

\section{DISCUSSION}

The results presented herein illustrate that PC12 cells express NGF receptors at their surface in a cell cycle-specific manner. Interpretation of this work is dependent on a clear appreciation of the techniques that were used in making the observations. On the one hand, immunofluorescence resulting from the binding of antibodies to the extracellular domain of the receptor is detected and quantitated with flow cytometric analysis; on the other hand, cytolocalization is confirmed by fluorescence microscopy. The use of flow cytometry also allows for the evaluation of receptor expression as a function of cell cycle phase in exponentially growing populations. Such an approach does not require previous synchronization of the cultures and therefore reflects the natural state of the cells under optimal growth conditions. The validity of this approach is underlined by the fact that numerous controls are performed for each analysis. In a single double-labeling experiment, for example, 12 different combinations of the various antibodies are performed and analyzed. The sensitivity is evaluated by increasing the amount of primary antibody as well as by applying several different antibodies recognizing distinct epitopes within the same protein. Such conditions allow for, respectively, saturation of the available sites and amplification of the fluorescence signal.

A molecular approach, i.e., biotinylation of surface proteins, followed by Western analysis, was performed to confirm or refute the observations made with flow cytometric analysis. To obtain populations of cells enriched in a given cell cycle phase, we first

by using FITC-labeled anti-mouse. Cells were labeled with 192-IgG and Ab267 as described in Figure 2 and with propidium iodide as described in Materials and Methods. Similar results were obtained with Hoechst labeling for cell cycle distribution. 
A

early $G 1$ late $G 1$

G2

M

\section{Control}
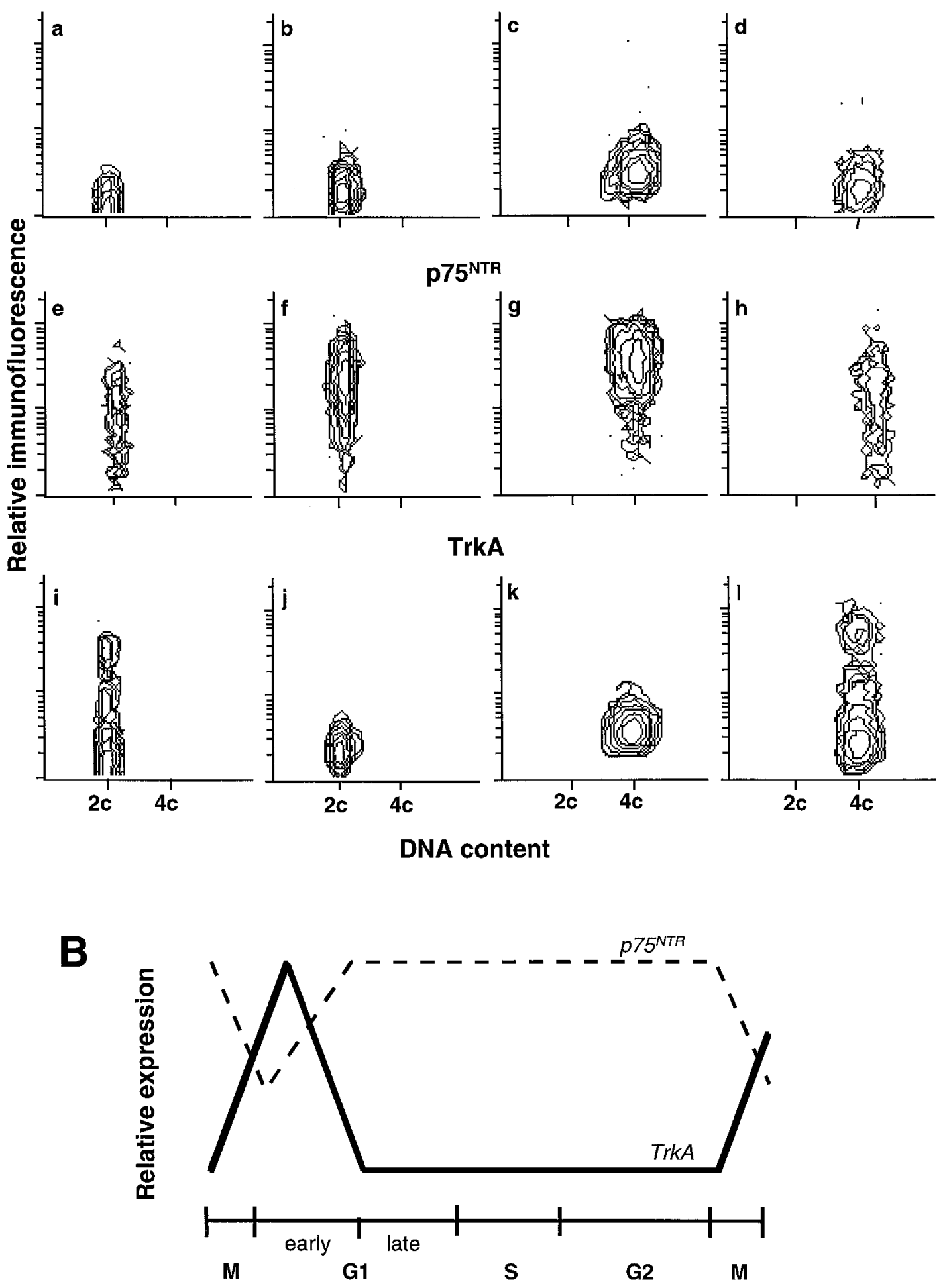

Figure 4. Refined analysis of cell cycle expression of NGF receptors. $A$, Bivariate contour plots obtained in a triple-labeling experiment after gating cells of different subpopulations and phases of the cell cycle of exponentially growing PC12. Shown are control $(a-d)$, p75 $5^{\mathrm{NTR}}$ expression $(e-h)$, and TrkA expression $(i-l)$ in early $\mathrm{G} 1(a, e, i)$, late $\mathrm{G} 1(b, f, j), \mathrm{G} 2(c, g, k)$, and M phases $(d, h, l)$. The control shown $(a)$ is an incubation of a second antibody (FITC-labeled anti-rabbit) only. Similar results were obtained by using Phycoerythrin-labeled anti-mouse. $B$, Model of relative expression of NGF receptors at the surface of PC12 cells. Shown is the relative surface expression of p $75^{\mathrm{NTR}}$ (dotted line) and TrkA (solid line) during the PC12 cell cycle. Cells were labeled with 192-IgG and Ab267 as described in Figure 2 and with Hoechst as described in Materials and Methods. 
A

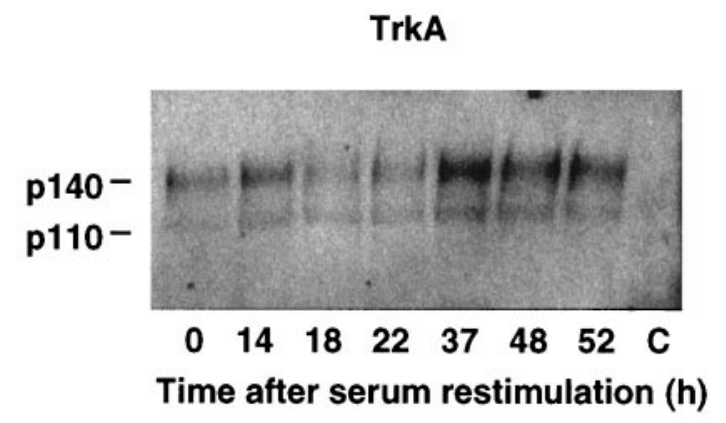

B
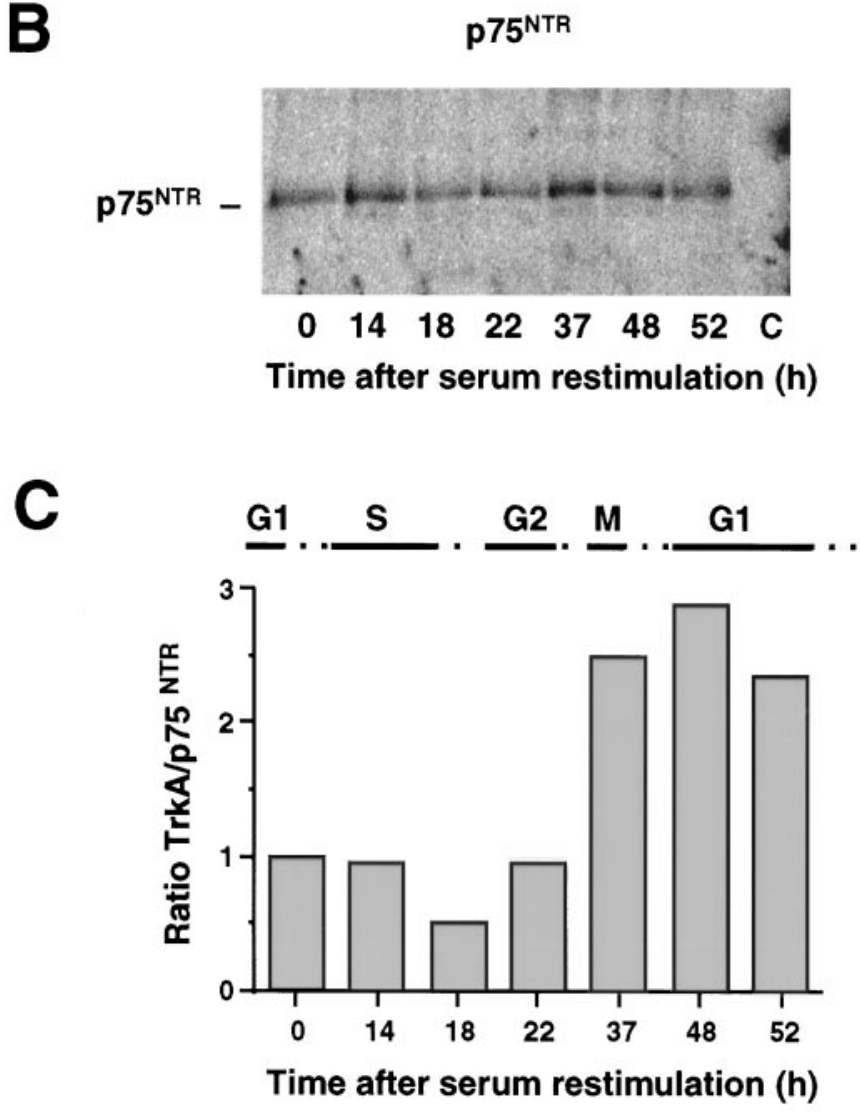

Figure 5. Western analysis of NGF receptors expressed at the surface of PC12 cells. PC12 cells were synchronized by serum starvation and restimulated by serum addition, as previously described (Rudkin et al., 1989). A, TrkA surface expression. $B$, p $75^{\mathrm{NTR}}$ surface expression in serum-starved cells exposed to serum. $C$, Changes in the ratio of TrkA to $\mathrm{p} 75^{\mathrm{NTR}}$ during the cell cycle of PC12 cells synchronized by serum starvation. The broken line above the graph represents the corresponding cell cycle phase, based on cumulative analysis of the cell line over the past 8 years and on observations of histone RNA expression, thymidine or BrdU incorporation, and cell number. RTA and 9993 were used for the detection of TrkA and $\mathrm{p} 75^{\mathrm{NTR}}$, respectively. Comparable results were obtained in two separate experiments.

must synchronize cultures and then allow them to proceed through the cell cycle in a synchronous manner. The sensitivity of this protocol, therefore, is dependent on the degree of synchrony. Ideally, close to $100 \%$ synchrony would be required to reflect the precise expression of a given protein as a function of cell cycle phase. With PC12 cells the synchronization procedure that was used offers a degree of synchrony of $\sim 70-80 \%$ on average. This is sufficiently high to confirm the observation made by flow cytometric analysis, i.e., that there is an increase in the ratio of TrkA to $\mathrm{p} 75^{\mathrm{NTR}}$ at the cell surface in M and early $\mathrm{G} 1$ phases. However, the absence of TrkA in a given cell cycle phase cannot be determined by this approach, because there is a residual signal attributable to the unsynchronized cell population. In this regard, flow cytometric analysis of the exponentially growing (asynchronous) cultures is much more precise.

In binding studies performed on exponentially growing PC12 cultures, $\sim 90 \%$ of the receptors on a cell are considered to be low affinity, whereas 5-10\% are high affinity (Meakin and Shooter, 1991; Weskamp and Reichardt, 1991; Mahadeo et al., 1994). These studies reflect an average picture of the cell culture, because individual cell populations cannot be distinguished by using such techniques. This interpretation is based, therefore, on the assumption that all cells in the population express both types of receptors at their surface. The present results offer a different interpretation. Inasmuch as the $\operatorname{TrkA} / \mathrm{p} 75^{\mathrm{NTR}}$ heterodimer is considered as the high-affinity receptor for NGF (Hempstead et al., 1991; Battleman et al., 1993; Barker and Shooter, 1994), the flow cytometric analysis has allowed for the detection of distinct cell populations expressing these proteins at the cell surface. They suggest that there are at least two subpopulations of cellsthe majority of which expresses only one type of receptor of low affinity, whereas the remaining cells express the components comprising the high-affinity receptor. These observations are of particular import for the study of receptor complex formation (i.e., homodimers or heterodimers of TrkA and $\mathrm{p} 75^{\mathrm{NTR}}$ ) and NGF signal transduction in general, using the PC12 cell model.

It is well established that the presence of TrkA is essential for the triggering of differentiation, the induction of c-fos expression, and the anti-mitogenic effect of NGF (Loeb and Greene, 1993; Kaplan and Stephens, 1994). If this receptor is absent in PC12 cells (or expressed at extremely low levels), these responses are not detectable. The results presented herein clearly are in agreement with these reports and offer another dimension to the understanding of the importance of the role of each receptor in the NGF response. In the light of our previous studies (Rudkin et al., 1989) certain G1-specific responses to NGF (e.g., induction of c-fos) would be a direct result of the surface expression of TrkA in the $\mathrm{G} 1$ phase. The surface expression of $\mathrm{p} 75^{\mathrm{NTR}}$ in late $\mathrm{G} 1, \mathrm{~S}$, and G2 phases indicates that the survival/progression response provoked by NGF in exponentially growing cells in the absence of serum is attributable to the presence of this receptor (for discussion, cf. Rudkin et al., 1989). This interpretation is supported by reports suggesting that, depending on the cellular context, p $75^{\text {NTR }}$ can stimulate a pro-apoptotic signal in the absence of NGF that is neutralized in its presence (for discussion, cf. Bredesen and Rabizadeh, 1997). Another interpretation would be to assume that TrkA is present at the cell surface during this part of the cell cycle at levels, undetectable by the approaches described herein, that would be too low to stimulate c-fos expression or cell cycle arrest but that would be sufficient to permit survival. In either case, the change in the relative amounts of TrkA to $\mathrm{p} 75^{\mathrm{NTR}}$ clearly would result in differences in signaling in response to NGF throughout the cell cycle, differences that have been evidenced previously (Rudkin et al., 1989).

These studies offer elucidation of the cell cycle phase-specific action of NGF. Figure 6 illustrates a model summarizing the results discussed in this report. In this model the physiological response observed as a function of cell cycle phase initially is attributable to the regulated surface expression of $p 75^{\text {NTR }}$ and TrkA. That TrkA is expressed at the cell surface in the $M$ and 
Figure 6. Model illustrating selected physiological responses to NGF as a function of TrkA and p $75^{\text {NTR }}$ expression throughout the cell cycle. See Discussion.

early G1 phases of the cell cycle suggests that cells should commit to differentiate at the very beginning of the cell cycle. The in vivo studies of Waid and McLoon (1995) on the timing of differentiation of ganglion cells in the developing chick retina indicate that these cells start to differentiate very rapidly (within $15 \mathrm{~min}$ ) after the final mitosis. Although the actual mechanisms are not clear, such observations speak to the importance of the cell being able to respond to a differentiation signal at a specific moment relative to cell division.

Regulation of surface expression of membrane proteins is a means for modulating cellular response to surrounding stimuli. Such considerations are evident from studies of expression of growth factor receptors or adhesion molecules during development and in cellular models in vitro. To our knowledge, this study offers the first description of cell cycle phase-specific surface expression of a growth factor receptor correlating with physiological and molecular responses to the natural ligand, as initially described in Rudkin et al. (1989). Studies of Zanellato et al. (1993) in C6 glioma cells suggest that the cellular distribution of TrkA might vary between a perinuclear and a membrane localization as a function of the growth state. Others have observed the preferential expression of a membrane protein, the neural surface receptor p65/p95, during the $\mathrm{S}, \mathrm{G} 2$, and $\mathrm{M}$ phases of the cell cycle in mouse neural embryonic precursors (Rebai et al., 1997). Clearly these observations speak to the fact that the regulation of surface expression of membrane proteins during the cell cycle may offer the cell another level of refinement in its capacity to respond to the environment.

It is conceivable that other aspects of signaling infrastructure also may vary according to the cell cycle phase. Indeed, NGF treatment of PC12 cells affects the expression and activity of cell cycle regulatory proteins, resulting in the accumulation of cells in the G1 phase (Dobashi et al., 1995; Yan and Ziff, 1995; van Grunsven et al., 1996a,b). The organization of chromatin also varies throughout the cell cycle, as does nuclear transport, thus offering further levels of controlling the growth factor response as a function of cell cycle phase. The observations presented herein leave us with numerous novel lines of study that should contribute to understanding the mechanism of NGF action and perhaps that of other neurotrophic factors and their receptors.

\section{REFERENCES}

Barbacid M (1994) The Trk family of neurotrophin receptors. J Neurobiol 25:1386-1403.
Barker PA, Shooter EM (1994) Disruption of NGF binding to the lowaffinity neurotrophin receptor $\mathrm{p} 75^{\mathrm{LNTR}}$ reduces NGF binding to TrkA on PC12 cells. Neuron 13:203-215.

Battleman DS, Geller AI, Chao MV (1993) HSV-1 vector-mediated gene transfer of the human nerve growth factor receptor $\mathrm{p} 75^{\mathrm{hNGFR}}$ defines high-affinity NGF binding. J Neurosci 13:941-951.

Bredesen DE, Rabizadeh S (1997) p75 ${ }^{\text {NTR }}$ and apoptosis: Trkdependent and Trk-independent effects. Trends Neurosci 20:287-290.

Casaccia-Bonnefil P, Carter BD, Dobrowsky RT, Chao MV (1996) Death of oligodendrocytes mediated by the interaction of nerve growth factor with its receptor p75. Nature 383:716-719.

Chao MV (1994) The p75 neurotrophin receptor. J Neurobiol 25:1373-1385.

Dobashi Y, Kudoh T, Matsumine A, Toyoshima K, Akiyama T (1995) Constitutive overexpression of $\mathrm{Cdk} 2$ inhibits neuronal differentiation of rat pheochromocytoma PC12 cells. J Biol Chem 270:23031-23037.

Ekstrand AJ, Liu L, He J, Hamid ML, Longo N, Collins VP, James CD (1995) Altered subcellular location of an activated and tumourassociated epidermal growth factor receptor. Oncogene 10:1455-1460.

Frade JM, Rodriguez-Tébar A, Barde YA (1996) Induction of cell death by endogenous nerve growth factor through its $\mathrm{p} 75$ receptor. Nature 383:166-168.

Geido E, Giaretti W, Nüsse M (1990) Detection of M and early-G1 phase cells by scattering signals combined with identification of $\mathrm{G} 1, \mathrm{~S}$, and G2 phase cells. Methods Cell Biol 33:149-156.

Greene LA, Tischler AS (1976) Establishment of a noradrenergic clonal line of rat adrenal pheochromocytoma cells which respond to nerve growth factor. Proc Natl Acad Sci USA 73:2424-2428.

Hempstead BL, Martin-Zanca D, Kaplan D, Parada LF, Chao MV (1991) High-affinity NGF binding requires co-expression of the trk proto-oncogene and the low-affinity NGF receptor. Nature 350:678-683.

Jing S, Tapley P, Barbacid M (1992) Nerve growth factor mediates signal transduction through Trk homodimer receptors. Neuron 9:1067-1079.

Kaplan DR, Stephens RM (1994) Neurotrophin signal transduction by the Trk receptor. J Neurobiol 25:1404-1417.

Kaplan DR, Hempstead BL, Martin-Zanca D, Chao MV, Parada LF (1991) The trk proto-oncogene product: a signal transducing receptor for nerve growth factor. Science 252:554-557.

Lee K, Li E, Huber J, Landis SC, Sharpe AH, Chao MV, Jaenisch R (1992) Targeted mutation of the gene encoding the low-affinity NGF receptor $\mathrm{p} 75$ leads to deficits in the peripheral sensory nervous system. Cell 69:737-749.

Loeb DM, Greene LA (1993) Transfection with trk restores "slow" NGF binding, efficient NGF uptake, and multiple NGF responses to NGFnonresponsive PC12 cell mutants. J Neurosci 13:2919-2929.

Mahadeo D, Kaplan L, Chao MV, Hempstead BL (1994) High-affinity nerve growth factor binding displays a faster rate of association than p140 ${ }^{\text {trk }}$ binding. J Biol Chem 269:6884-6891.

Meakin SO, Shooter EM (1991) Molecular investigations on the highaffinity nerve growth factor receptor. Neuron 6:153-163.

Rabizadeh S, Oh J, Zhong L-T, Yang J, Bitler CM, Butcher LL, Bre- 
desen DE (1993) Induction of apoptosis by the low-affinity NGF receptor. Science 261:345-348.

Rea S, James DE (1997) Moving Glut4: the biogenesis and trafficking of Glut4 storage vesicles. Diabetes 46:1667-1677.

Rebai N, Almazan G, Wei L, Greene MI, Saragovi HU (1997) A p65/ p95 neural surface receptor is expressed at the S-G2 phase of the cell cycle and defines distinct populations. Eur J Neurosci 8:273-281.

Rudkin BB, Lazarovici P, Levi B-Z, Abe Y, Fujita K, Guroff G (1989) Cell cycle-specific action of nerve growth factor in PC12 cells: differentiation without proliferation. EMBO J 8:3319-3325.

van Grunsven LA, Billon N, Savatier P, Thomas A, Urdiales JL, Rudkin BB (1996a) Effect of nerve growth factor on the expression of cell cycle regulatory proteins in PC12 cells: dissection of the neurotrophic response from the anti-mitogenic response. Oncogene 12:1347-1356.

van Grunsven LA, Thomas A, Urdiales JL, Machenaud S, Choler P, Durand I, Rudkin B (1996b) Nerve growth factor-induced accumula- tion of PC12 cells expressing cyclin D1: evidence for a G1 phase block. Oncogene 12:855-862.

Waid DK, McLoon SC (1995) Immediate differentiation of ganglion cells following mitosis in the developing retina. Neuron 14:117-124.

Weskamp G, Reichardt LF (1991) Evidence that the biological activity of NGF is mediated through a novel subclass of high-affinity receptors. Neuron 6:649-663.

Yan G-Z, Ziff EB (1995) NGF regulates the PC12 cell cycle machinery through specific inhibition of the $\mathrm{Cdk}$ kinases and induction of cyclin D1. J Neurosci 15:6200-6212.

Yankner BA, Shooter EM (1982) The biology and mechanism of action of nerve growth factor. Annu Rev Biochem 51:845-868.

Zanellato A, Facci L, Petrelli L, Dal Toso R, Skaper SD (1993) Characterization and growth-dependent regulation of the nerve growth factor receptor gp140 ${ }^{\text {trk }}$ in C6 glioma cells. Mol Brain Res 23:299-309. 